\title{
Agôn
}

Revue des arts de la scène

$5 \mid 2012$

L'entrée en scène

\section{« Répétitions, variations »}

Capucine Berthon, Camille Khoury, Simon Pineau, Julie Rossello-Rochet et Martynas Tyskus

\section{(2) OpenEdition}

\section{Journals}

Édition électronique

URL : http://journals.openedition.org/agon/2694

DOI : 10.4000/agon.2694

ISSN : 1961-8581

Éditeur

Association Agôn

Référence électronique

Capucine Berthon, Camille Khoury, Simon Pineau, Julie Rossello-Rochet et Martynas Tyskus, " "Répétitions, variations » », Agôn [En ligne], 5 | 2012, mis en ligne le 14 janvier 2013, consulté le 14 septembre 2020. URL : http://journals.openedition.org/agon/2694

Ce document a été généré automatiquement le 14 septembre 2020.

Association Agôn et les auteurs des articles 


\title{
« Répétitions, variations »
}

\author{
Capucine Berthon, Camille Khoury, Simon Pineau, Julie Rossello-Rochet et \\ Martynas Tyskus
}

1 Entrer, au propre et par définition, signifie entrer de l'extérieur vers l'intérieur. Il s'agit du franchissement d'une frontière qui sépare deux espaces distincts ; un seuil. Dans son recueil de poèmes De seuil en seuil, Paul Celan crée des variations incessantes autour de ces passages qu'il envisage comme des créateurs de métamorphoses sensibles. Lorsque le dernier seuil semble avoir été franchi, demeure encore celui de l'œil de l'autre : « par deux nagent les morts, / par deux baignés de vin. [...] Toi, lance le dé, encore, /et plonge dans l'oil de l'un d'eux. »1

2 Lorsque nous avons commencé à réfléchir à une forme théâtrale autour de la question de "l'entrée en scène ", nous est venue l'idée d'un extrait très précis d'On ne badine pas avec l'amour d'Alfred de Musset, la scène V, Acte II, qui se déroule près d'une fontaine dans un bois :

Entre Perdican, lisant un billet.

PERDICAN. « Trouvez-vous à midi à la petite fontaine. » Que veux dire cela? Tant de froideur, un refus si positif, si cruel, un orgueil si insensible, et un rendez-vous pardessus-tout? Si c'est pour me parler d'affaires, pourquoi choisir un pareil endroit? Est-ce une coquetterie? Ce matin, en me promenant avec Rosette, j'ai entendu remuer dans les broussailles, et il m'a semblé que c'était un pas de biche. Y a-t-il ici quelque intrigue?

Entre Camille.

CAMILLE. Bonjour, cousin. ${ }^{2}$

Pourquoi l'intuition de cette scène ? Le personnage du Baron, au début de la pièce, dit à Maître Bridaine :

Regardez par cette fenêtre; ne voyez-vous pas que mes gens se portent en foule à la grille? Mes deux enfants arrivent en même temps; voilà la combinaison la plus heureuse. J'ai disposé les choses de manière à tout prévoir. Ma nièce sera introduite par cette porte à gauche, et mon fils par cette porte à droite. Qu'en dites-vous? Je me fais une fête de voir comment ils s'aborderont, ce qu'ils se diront. ${ }^{3}$

Dans cet extrait, le baron met en scène l'entrée de Camille et Perdican de sorte que, non seulement ils se rencontrent, mais qu'ils s'éprennent l'un de l'autre. La pièce d'Alfred de Musset, à l'intrigue sentimentale de prime abord légère, est un tour de force autour 
de la question de la rencontre amoureuse manquée, de l'échec et de la mort. Si " rencontrer " désigne pour Montaigne le fait d'exister quelque part ${ }^{4}$, se rencontrer pourrait être le fait d'exister l'un pour l'autre quelque part. Si selon le baron, l'entrée de deux personnes détermine leur rencontre amoureuse, alors cette entrée devient déterminante car on ne saurait badiner avec l'amour, au risque de n'exister nulle part.

5 À partir de cette scène jouée et rejouée, comme l'est une "scène de conservatoire ", nous avons inventé des répétitions-variations d'entrée en scène, participant à l'usure de ce thème. Elle offre deux entrées aux comédiens : la première, celle du personnage de Perdican, la seconde, celle de celui de Camille. Ces entrées ont été tantôt envisagées du point de vue du dispositif scénique (entrée à cour/jardin depuis les coulisses, « entrée en piste » : au centre en frontal, en écartant les pendrillons, entrée depuis le public), tantôt du point de vue du temps, en créant une déclinaison d'entrées ratées (entrées trop tôt, trop tard), et enfin, du point de vue de l'esthétique, concomitante, indirectement, avec une certaine historicité (entrer en prenant en compte «le quatrième mur ", entrer en laissant son corps en coulisses par la substitution des corps des acteurs à des marionnettes ou en ne laissant entrer qu'un bras, "entrée adressée » en prenant en compte le public comme le ferait M. Loyal dans un cirque...). Nous avons imaginé des entrées par explication dramaturgique, en dégageant des questions à partir du texte: qu'est-ce qu'entrer "comme dans un rêve»? Qu'est-ce que "se rencontrer à la croisée des chemins » sur un plateau de théâtre? Qu'est-ce qu'entrer et sortir grâce à la lumière ? Ces différents critères offrent des combinaisons de multiples entrées en scène qui proposent une série d'expériences nourrissant notre démarche d'observation quant à la thématique.

\section{NOTES}

1. CELAN ; Paul. De seuil en seuil. Trad. Valérie Briet. Paris : Christian Bourgois, 1991.

2. « (...) j'ai cru m'apercevoir, à tort ou à raison, que vous me quittiez tristement ce matin. Vous m'avez pris la main malgré moi, je viens vous demander de me donner la vôtre. Je vous ai refusé un baiser, le voilà.

Elle l'embrasse.

Maintenant, vous m'avez dit que vous seriez bien aise de causer de bonne amitié. Asseyez-vous là et causons. Elle s'assoit.

PERDICAN. Avais-je fait un rêve, ou en fais-je un autre en ce moment?»

MUSSET, Alfred (de). On ne badine pas avec l'amour. Paris : Folio Théâtre, 1994. [1833]. P.62.

3. Ibid. Acte I, scène 2. P. 30

4. MONTAIGNE : se rencontrer «exister quelque part », 1580. In les Essais, II, 10, éd. P. Villey et V.-L. Saulnier, p. 418). In CNRTL (Centre National de Ressources Textuelles et Lexicales). 